\title{
EDITORIAL
}

\section{Resolving disagreement during end of life care in the critical care unit: The case for communication not arbitration}

Michael Hartwick MD ${ }^{1}$

Gwynne Jones MD²
${ }^{1}$ Division of Critical Care Medicine, Division of Palliative Care Medicine, Department of Medicine, The

Ottawa Hospital, University of Ottawa, Ottawa, Ontario.

2 Division of Critical Care Medicine, Department of Medicine, The Ottawa Hospital, University of Ottawa, Ottawa, Ontario.

Manuscript accepted 30th July, 2010

Clin Invest Med 2010; 33 (4): E219-E222.
Clinical medicine tries to resolve the uncertainties of diagnosis and prognosis. The natural history of the illness is repeatedly examined using both our own knowledge base and that of our colleagues. This is an iterative hypothesis testing process that starts with the history and physical examination and progresses with increasingly complex tests. Thus, the uncertainty of diagnosis and prognosis is diminished but never absolutely eliminated because of the limits of both our knowledge and our tests. Our scientific hypothesis testing, using the reductionist process, by which the whole can be deduced from the sum of its parts, has some human limitations. Science deals with generalities that strive to be objective and value free. In contradistinction, the patient is a unique individual, with deeply embedded personal values, whose wholeness is greater than the sum of his/her parts. For example, the patient may have qualities with descriptors such as insightful, tender, suffering or anxious. Thus, there is often a tension between medicine and science as well as a tension between the wishes of the patient, or Sub- stitute Decision Maker (SDMs), and those of the health care team.

How then does the health care team promote a process that eases this tension and results in an outcome that is acceptable to all involved? Let us eliminate, initially, the question of resource use and its inevitable opportunity cost. Distributive justice can never be a part of the health care team's argument for limitation of an individual's right to care. This is a societal problem that we, as health care workers, in a finite system must be aware of, but it cannot impinge upon individual care decisions. Rather than societal, the focus of the process must be individual. Dialogue must occur, in which the patient or SDM may give a clear picture of illness status and insight into current life activities and life quality. The health care team must first listen and attempt to understand this picture before communicating their thoughts on the current diagnosis and prognosis and how this may impact on the patient's life. ${ }^{1}$ If the physician has fears about death or severe morbidity, which would likely limit 
life quality or duration, these concerns must be compassionately explained and the response of the patient or SDM acknowledged. This process must be transparent and inclusive so that a sense of solidarity between the health care team, the patient and the family is achieved.

A principle requirement is that the treating team and the patient or SDM are engaged in dialogue throughout the illness. The earlier effective communication begins, and the earlier respective agendas are acknowledged, the sooner rapport will be established and trust developed. ${ }^{2}$ Thus, the initial meeting is the most important part of the process of bonding between the patient/SDM and the health care team. Time spent at this first encounter will set the tone, expedite future meetings, enable the role of the whole health care team and initiate the process of solidarity and trust amongst all members. The longer the delay in establishing effective dialogue the greater the difficulty in establishing that vital trust and solidarity between the health care team and the patient/SDM. The nature of critical care medicine places time at a premium and often crucial decisions are required early - before trust and a sense of a common purpose have been formed. Where possible, critical care practitioners should enlist the help of other longstanding care providers who have already established these strong relationships with the patient/SDM. Clinical skill must be used to minimize the pressure of time and create circumstances where safe communication can emerge.

Critical care teams must also acquire and hone a unique subset of communication skills that are both efficient and powerful enough to rapidly establish rapport and the trusting foundation on which good decision making and conflict resolution can be supported. Effective early communication has been shown to be therapeutic whereas poor communication may lead to misunderstanding, mistrust and deepening conflicts. $^{3-8}$

The paper, "A Framework for Resolving Disagreement During End of Life Care in the Critical Care Unit", by Karen Choong and colleagues in this issue of Clinical and Investigative Medicine is a logical and thoughtful exposition of the difficulties arising in the process of withdrawing life sustaining therapy (WLST) in Canada's intensive care units. ${ }^{9}$

In the text and case example, the authors succeed in demonstrating a compassionate human response and also highlight the immense burden of responsibility that must be borne in advocating for or against the discontinuation of life sustaining therapy. Although this is not the first effort to create and describe a resolution strategy for WLST disputes, the authors' thorough and transparent literature review yields a comprehensive description of a resolution process applicable within the Canadian Critical Care context and complying with Canadian legal precedent. ${ }^{10-12}$ One of the strengths of this newly published framework is the breadth of the review from which it was generated. By reviewing the literature, college policies, ethical principles and the law, the authors provide the reader with a clear overview of the process - although every individual step is enormously complex. When the life of another person depends on the outcome of the process, the responsibility must be shared and viewed from many perspectives. The ten-step process outlined by the authors demonstrates inclusiveness at all levels. This ensures the assembly of as many perspectives as is possible; however, the reader is given little detail as to how the ten elements were selected and ordered from the content reviewed. Further insight into both the selection process and consensus process for the creation of the framework would be of great assistance for readers wishing to apply it to their local context, and for those in the field hoping to further this work with future contributions.

The paper may, paradoxically, be regarded as documenting a failure of the clinical process in that the case presented eventually needed resolution through the Superior Court of Ontario. If the authors' assertion that conflicts about WLST between SDM and physicians have become increasingly common is true, then it is only through meticulous attention to the first five steps of this process that this tendency can be 
changed. ${ }^{13,14}$ The transition point in the framework by Choong et al. occurs at element 5, "When it is clear that no agreement between SDMs and clinicians can be reached, initiate a third party arbitration process". This transition indicates a gulf between all parties and represents a disparity between the clinical experience and the human experience ${ }^{4}$.

It is prudent to create and understand comprehensive frameworks such as the one presented by Karen Choong and colleagues, in order to resolve very rare, but seemingly intractable disputes about WLST in Canadian critical care units. Perhaps the strongest marker of the success of Choong et al.'s process would be if most users could not recall its last five elements. Elements six through ten of the process deal with legal issues related to arbitration of a dispute. The need for arbitration is symptomatic of a breakdown in communication. Future energies and initiatives must focus on practical, tangible strategies to equip critical care providers with excellent communication and conflict resolution skills. It is these skills that allow the clinician to weave the humanity and the science of life together. ${ }^{15}$ Communication skills that resolve goals of care in a clear, compassionate and transparent fashion, promote good decisions that are congruent with the patient's life. We feel that the provision of good medicine is significantly compromised if the health care team, the patients and their families are not all in agreement with the treatment goals, whether this be active aggressive curative therapy or withdrawal of life-sustaining therapy. This requirement for excellent communication and conflict resolution skills will ensure the long-term moral and overall wellbeing of the care providers as well as provision of excellent care to patients and their families. Is this a council of perfection in large impersonal hospitals and intensive care units? Possibly, but it is surely worth aiming for.

\section{References}

1. Truog RD, Campbell ML, Curtis JR, Haas CE, Luce JM, Rubenfeld GD, Rushton CH, Kaufman DC; American Academy of Critical Care Medicine. Recommendations for end-of-life care in the intensive care unit: a consensus statement by the American College [corrected] of Critical Care Medicine. Crit Care Med 2008; Mar; 36(3):953-63.

2. Curtis JR, White D. Practical Guidance for Evidence-Based ICU Family Conferences. Chest 2008;134:835-43.

3. McDonagh JR, Elliott TB, Engelberg RA, Treece PD, Shannon SE, Rubenfeld GD, et al. Family satisfaction with family conferences about end-of-life care in the intensive care unit: increased proportion of family speech is associated with increased satisfaction. Crit Care Med 2004;32(7):1484-8.

4. Weiner JS, Roth J. Avoiding iatrogenic harm to patient and family while discussing goals of care near the end of life. J Palliat Med 2006;9(2):451-63

5. Lautrette A, Darmon A, Megarbane B, Joly L, Chevret $\mathrm{S}$, Adrie $\mathrm{C}$, et al. A communication strategy and brochure for relatives of patients dying in the ICU. $N$ Engl J Med 2007;356:469-78.

6. Selph RB, Shiang J, Engelberg R, Curtis JR, White DB. Empathy and life support decisions in intensive care units. J Gen Intern Med 2008; 23(9):1311-7.

7. Abbott KH, Sago JG, Breen CM, Abernethy AP, Tulsky JA. Families looking back: one year after discussion of withdrawal or withholding of life-sustaining support. Crit Care Med 2001; 29(1):197-201.

8. Stapleton RD, Engelberg RA, Wenrich MD, Goss CH, Curtis JR. Clinician statements and family satisfaction with family conferences in the intensive care unit. Crit Care Med 2006; 34(6):1679-85.

9. Choong K, Cupido C, Nelson E, Arnold DM, Burns K, Cook D, Meade M, On behalf of ACCADEMY (Academy of Critical Care: Development, Evaluation, and Methodology, McMaster University): A Framework for Resolving Disagreement During End of Life Care in the Critical Care Unit. Clinical and Investigative Medicine 2010; 33(4):E240-E253

10. Bay Area Network of Ethics Committees Nonbeneficial Treatment Working Group: Nonbeneficial or futile medical treatment: Conflict resolution guidelines for the San Francisco Bay Area. West J Med 1999; 170 : $287-290$

11. Fine RL: Medical futility and the Texas Advance Directives Act of 1999. Proc (Bayl Univ Med Cent) 2000; 13:144-147 
12. Fine RL, Mayo TW: Resolution of futility by due process: Early experience with the Texas Advance Directives Act. Ann Intern Med 2003; 138:743-746

13. Breen C, Abernathy A, Abott K, Tulsky J. Conflict associated with decisions to limit life-sustaining treatment in intensive care units. $J$ Gen Intern Med 2001;16:283-89.

14. Way J, Back AL, Curtis JR. Withdrawing life support and resolution of conflict with families. BMJ. 2002; 325(7376): 1342-5

15. Curtis JR, Burt RA. Futility in the intensive care unit: hard cases make bad law. Crit Care Med 2010;

38(8):1742-3.
Correspondence to:

Dr. Gwynne Jones

Division of Critical Care Medicine The Ottawa Hospital (General Campus)

501 Smyth Rd.

Ottawa, ON. Canada.

K1H 8L6

Email: gjones@ottawahospital.on.ca 